\title{
A Brief Review of Molecular Markers to Analyse Medicinally Important Plants
}

\author{
Sevgi Marakli ${ }^{1 *}$
}

Abstracts: Suitable identification and characterisation of medicinal plants are necessary for conservation of plant resources, investigations of genes associated with desirable traits, and understanding of evolutionary relationships. Therefore, various molecular marker techniques such as RAPD, AFLP, SSR and ISSR, SNP, SCoT, ITS and SCAR have been improved to provide detail information about genomes, which were not previously possible with only phenotypic methods. This brief review represents usage of these markers for molecular diversity analyses of medicinally important plants.

Keywords: AFLP, ITS, RAPD, SSR, SNP, SCoT, SCAR

\section{Introduction}

Herbal medicines play a significant role as an alternative to synthetic pharmaceuticals, reaching \$115 billion by 2020 [1]. For this reason, conservation of endemic, threatened and endangered medicinal species, improving high-quality cultivars with desirable traits and even knowledge of the germplasm diversity have gained importance in the past decades [2]. Hence, different molecular markers have been commonly used for these purposes to give detailed information about genomes which is not possible with phenotypic methods.

DNA barcoding provides species-level identifications using short standard DNA regions, known as DNA barcodes or markers [3]. Ideal DNA markers should be highly polymorphic in nature, codominant inheritance, frequent occurrence in the genome, fast and easy testing, high reproducibility, and even easy exchange of data among laboratories [4]. DNA barcoding has been widely applied to answer a broad range of questions related

\footnotetext{
${ }^{1}$ Amasya University, Faculty of Arts and Sciences, Department of Biology, 05100 Amasya, Turkey

*Corresponding author: sevgi.marakli@amasya.edu.tr
} 
to taxonomy, molecular phylogenetic, population genetics, and biogeography $[5,6,7]$, as well as trade control of flora, fauna and food products $[8,9,10]$.

In this brief review, detail information of molecular marker techniques: Random Amplified Polymorphic DNA (RAPD), Amplified Fragment Length Polymorphism (AFLP), Microsatellites, or Simple Sequence Repeats (SSR), Inter Simple Sequence Repeat (ISSR) Single Nucleotide Polymorphism (SNP), Start Codon Targeted Polymorphism (SCoT), ribosomal internal transcribed spacer (ITS) and SequenceCharacterised Amplified Region (SCAR) in medicinal plants is discussed.

\section{RAPD}

This technique is based on the amplification of genomic DNA with single primer of an arbitrary nucleotide sequence with no previous information about the genome. Since most of the RAPD markers are dominant, it is not possible to distinguish whether the amplified DNA segment is heterozygous (two different copies) or homozygous (two identical copies) at a specific locus. However, in some cases, codominant RAPD markers, obtained as different-sized DNA segments amplified from the same locus, could be detected [11]. There are different studies reporting various polymorphism rates in medicinal plants by using this technique. Baruah et al. [2] reported that RAPD could be effectively used for genetic diversity evaluation among Cymbopogon species, cultivated for its essential oil Similar to Baruah et al. [2], Gantait et al. [12] used both RAPD and ISSR markers in Rauvolfia serpentina (L.) Benth. ex Kurz., which is one of the most vital pharmaceutically important plant from Apocynaceae family [13] to investigate post-germination genetic constancy. Furthermore, genetic fidelity of Amomum subulatum Roxb. used in Ayurvedic medicine [14] was also analysed during tissue culture process by using this marker [15]. Different experiments in medicinally important plants have shown that RAPD could be easily applied to detect polymorphisms in plant organs, and genetic diversity investigations of both intra- and inter-species.

\section{AFLP}

AFLP technique depends on the PCR amplification of restriction fragments obtained as a result of digestion of genomic DNA [16]. Many studies have analysed genetic diversity for different plant species using AFLP molecular markers [17]. Among molecular markers, AFLP produces much more reproducible bands, hence this technique is an 
important method to detect genetic variability of plants especially plants regenerated in vitro $[18,19]$. One of these studies was performed by Ebrahimi et al. [20] which genetic stability of in vitro regenerated plantlets of an endangered medicinal plant, Kelussia odorotissima Mozaff. native to Iran, was analysed.. In another study, Ghosh and Mandi [21] studied genotypes of Murraya koenigii growing in eastern Asia, revealing genetic variability in plants collecting from different altitudinal regions.

\section{SSR and ISSR}

SSRs consist of repeating units with one to six bp in length [22]. SSR markers have been extensively used in parentage analysis, genetic variation, molecular evolution, systematic taxonomy, linkage and comparative mapping, and functional diversity studies in plant species [23, 24]. Medicinal plant species have also been investigated by using SSR molecular marker technique. Kherwar et al. [25] analysed 24 SSRs in 36 varieties of guava (Psidium guajava L.), in addition to wild species. Genetic diversity, genetic characterisation of genotypes, cultivar identification and linkage mapping in guava were also being investigated using RAPD and AFLP markers [26, 27].

Next-generation sequencing (NGS) technologies have also been used to detect new SSR markers. Development of cumin (Cuminum cyminum L.) SSR markers were performed using Illumina Miseq NGS (next-generation sequencing) platform [28]. Genome-wide identification of SSRs was also carried out in tea plant (Camellia sinensis) [29]. Not only land plants but also aquatic plant species have also been analysed by using SSRs [30]. ISSR, as a modification of SSRs, offers such advantages such as high reproducibility, high polymorphism, low DNA requirements, easy handling, and high genomic distribution [31]. Chombe and Bekele [32] investigated the genetic diversity in populations of Aframomum corrorima (an economically important medicinal plant in Ethiopia) via seven ISSR primers. Moreover, Hashemifar and Rahimmalek [33] also reported that ISSR markers showed high efficiency in the evaluation of population diversity in Perovskia. Similar findings were also published for Thymus sibthorbii by Abraham et al. [34].

\section{SNP}

SNP is a DNA sequence variation occurring when a single nucleotide (A, T, G or C) differs among members of a species. SNP is one of the most abundant marker systems, 
and several computational methods, genotyping approaches and transcriptome resequencing have been performed to detect new SNPs [35, 36]. Generally, molecular markers are used for genetic diversity studies. In addition to these studies, researchers have also identified the differences between control and disease resistant and DNA regions associated with desirable traits by using these markers. Manivannan et al. [37] studied with pepper, reporting useful SNP markers related to pungency and disease resistance via NGS platform.

\section{SCoT}

SCoT markers, similar to others, are one of the reliable techniques due to lots of advantages such as efficient, informative, and even inexpensive. Primers used in this method are designed according to short conserved region surrounding the ATG translation start (or initiation) codon, showing the correlation between functional genes and their corresponding traits [38, 39, 40]. Hence, this method has been successfully applied in medicinal plants to explore their genetic variability [41, 42]. Some studies have used this marker alone or in combination with other markers. Mao et al. [42] suggested that combination of ISSR and SCoT markers showed more valuable and superior results than single analysis of ISSR and SCoT as a result of genetic diversity and population structure analyses in Senna obtusifolia L.

\section{ITS}

There are various reports for molecular systematic investigations of plants by using ITS regions. Many studies have been performed to identify Dendrobium species using ITS sequence analysis [43, 44]. Moreover, polymorphism ratios of Swertia species used in Indian medicine were also analysed by using different DNA barcodes including matK (megakaryocyte-associated tyrosine kinase), $r b c L$ (ribulose-bisphosphate carboxylase), psbAtrnH (photosystem II protein D1-structural RNA-His tRNA) and nrITS [45] where the highest interspecific divergence was obtained as a result of ITS analysis. Lee et al. [46] also successfully applied ITS technique to study genetic diversity in tea plant.

\section{SCAR}

Every plant DNA barcode method has also advantages, including failed PCR amplification, insufficient sequence variability between species, and incomplete sequence information $[47,48]$. Therefore, there could be three different ways to overcome 
these problems namely 1 . Usage of combination of at least two different markers; 2. Comparative analyses of genomic polymorphisms and 3. Investigation of new DNA barcode regions using plastid genome sequencing [49, 50, 51]. In the first method, RAPD technique, either alone or in combination with other techniques is extensively used for the genetic analyses of different medicinal plants, and even other organisms $[52,53]$. SCAR markers derived from the molecular cloning of RAPD fragments in medicinal plants are commonly applied because of its stability, sensitivity, and reliability [54]. This method amplifies only target-containing samples by using specific primers, and differentiates positive or negative amplification of target regions, as well as length polymorphisms of target regions by gel electrophoresis of closely related samples [53].

\section{Conclusion}

Molecular markers with low assay cost, convenience and fast and easy application and automation are undoubtedly valuable tools for population genetics and plant breeding programs $[55,56]$. Although each method has its benefits and limitations, suitable choice of one marker and/or combination of different markers could be easily used to overcome these disadvantages. Information provided in this brief review shows the basic description of different molecular techniques used in molecular diversity studies performed in medicinal plant species.

\section{References}

1. Global Industry Analyst, Inc., Herbal supplements and remedies market trends http://www.strategyr.com/MarketResearch/Herbal_Supplements_ and_Remedies_Market_Trends.asp, 2015.

2. Baruah, J., et al., Genetic diversity study amongst Cymbopogon species from NE-India using RAPD and ISSR markers. Industrial Crops and Products, 2017. 95: p. 235-243.

3. Hebert, P.D., A. Cywinska, S.L. Ball, JR, and deWaard., J.R., Biological identifications through DNA barcodes. Proceedings of the Royal Society of London B: Biological Sciences, 2003. 270: p. 313-321.

4. Joshi, S.P., P.K., Ranjanekar, and V.S. Gupta, Molecular markers in plant genome analysis. Current Science, 1999. 77: p. 230-240.

5. Hebert, P.D.N., and T.R., Gregory, The promise of DNA barcoding for taxonomy. Systematic Biology, 2005. 54: p. 852-859.

6. Hajibabaei, M., G.A., Singer, P.D., Hebert, and D.A., Hickey, DNA barcoding: how it complements taxonomy, molecular phylogenetics and population genetics. Trends in Genetics, 2007. 23: p. 167-172.

7. Valentini, A., F. Pompanon, and P. Taberlet, DNA barcoding for ecologists. Trends in Ecology \& Evolution, 2009. 24: p. 110-117. 
8. $\quad$ Eurlings, M., F., Lens, C., Pakusza, T., Peelen, J.J. Wieringa, and B., Gravendeel, Forensic identification of Indian snakeroot (Rauvolfia serpentina Benth. ex Kurz) using DNA barcoding. Journal of Forensic Sciences, 2013. 58: p. 822-830.

9. Janjua, S., W.K. Fakhar-I-Abbas, I.U. Malik, and J. Mehr, DNA mini-barcoding for wildlife trade control: A case study on identification of highly processed animal materials. Mitochondrial DNA Part A, 2016. 28: p. 544-456.

10. Di Pinto, A., et al., Packaged frozen fishery products: Species identification, mislabeling occurrence and legislative implications. Food Chemistry, 2016. 194: p. 279-283.

11. Williams, J.G.K. et al., DNA polymorphisms amplified by arbitrary primers are useful as genetic markers. Nucleic Acids Research, 1990. 18: p. 6531-6535.

12. Gantait, S., S., Kundu, L., Yeasmin, Md. N., Ali, Impact of differential levels of sodium alginate, calcium chloride and basal media on germination frequency of genetically true artificial seeds of Rauvolfia serpentina (L.) Benth. ex Kurz. Journal of Applied Research on Medicinal and Aromatic Plants, 2017. 4: p. 75-81.

13. Klyushnichenko, V.E., et al., Determination of indole alkaloids from $R$. serpentina and $R$. vomitoria by high performance liquid chromatography and high-performance thin layer chromatography. Journal of Chromatography, 1995. 704: p. 357-362.

14. Sharma, E., R., Sharma, and K.K., Singh, A boon for mountain populations: largecardamom farming in the Sikkim Himalaya. Mountain Research and Development, 2000. 20: p. 108-111.

15. Purohit, S., S.K., Nandi, S., Paul, M., Traiq, and L.M., Palni, Micropropagation and genetic fidelity analysis in Amomum subulatum Roxb.: A commercially important Himalayan plant. Journal of Applied Research on Medicinal and Aromatic Plants, 2017. 4: p. 21-26.

16. Vos, P., et al., AFLP: A new technique for DNA fingerprinting. Nucleic Acids Research, 1995. 23: p. 4407-4414.

17. Moya-Hernández, A., et al., Analysis of genetic diversity of Cucurbita ficifolia Bouché from different regions of Mexico, using AFLP markers and study of its hypoglycemic effect in mice. South African Journal of Botany, 2018. 116: p. 110-115.

18. Aversano, R., F., Di Dato, A., Di Matteo, L., Frusciante, and D., Carputo., AFLP analysis to assess genomic stability in solanum regenerants derived from wild and cultivated species. Plant Biotechnology Reports, 2011. 5: p. 265-271.

19. Mehta, R., V., Sharma, A., Sood, M., Sharma and R.K. Sharma, Induction of somatic embryogenesis and analysis of genetic fidelity of in vitro-derived plantlets of Bambusa nutans wall., using AFLP markers. European Journal of Forest Research, 2011. 130: p. 729-736.

20. Ebrahimi, M., A., Mokhtari, and R., Amirian, A highly efficient method for somatic embryogenesis of Kelussia odorotissima Mozaff., an endangered medicinal plant. Plant Cell, Tissue and Organ Culture, 2018. 132: p. 99-110.

21. Ghosh, S., and S.S., Mandi, Altitudinal effect in active principle content in Murraya koenigii (L) correlated with DNA fingerprinting study. Journal of Medicinal Plants Studies, 2018. 6: p. 20-26.

22. Bidichandani, S., T., Ashizawa, and P.I., Patel, The GAA triplet-repeat expansion in Friedreich ataxia interferes with transcription and may be associated with an unusual DNA structure. The American Journal of Human Genetics, 1998. 62: p. 111-121.

23. Zhu, H.Y., et al., Genome wide characterization of simple sequence repeats in watermelon genome and their application in comparative mapping and genetic diversity analysis. BMC Genomics, 2016. 17: p. 557.

24. Liu, S.R., et al., Construction of fingerprinting for tea plant (Camellia sinensis) accessions using new genomic SSR markers. Molecular Breeding, 2017. 37: p. 93.

25. Kherwar, D., K., Usha, S.V.A., Mithra, and B., Singh, Microsatellite (SSR) marker assisted assessment of population structure and genetic diversity for morpho-physiological traits in guava (Psidium guajava L.), Journal of Plant Biochemistry and Biotechnology. 2018, 27: p. 284-292. 
26. Hernandez-Delgado, S., Padilla-Ramirez, J.S., Nava-Cedillo, A., Mayek-Perez, N., Morphological and genetic diversity of Mexican guava germplasm. Plant Genet Resources, 2007. 5: p. 131-141.

27. Feria-Romero, I.A., et al., RAPD markers associated with quercetin accumulation in Psidium guajava. Biologia Plantarum. 2009, 53: p. 125-128.

28. Bharti, R., S., Kumar, M.J., Parekh, Development of genomic simple sequence repeat (gSSR) markers in cumin and their application in diversity analyses and cross-transferability. Industrial Crops and Products, 111: p. 158-164.

29. Liu, S., et al., Genome-wide identification of simple sequence repeats and development of polymorphic SSR markers for genetic studies in tea plant (Camellia sinensis). Molecular Breeding, 2018. 38: p. 59.

30. Zhai, S.H., G.S., Yin, X.H., Yang, Population genetics of the endangered and wild edible plant Ottelia acuminata in southwestern china using novel SSR markers. Biochemical Genetics, 2018. 56: p. 235-254.

31. Heidari, F.E., M., Rahimmalek, S., Mohammadi, M.H., Ehtemam, Genetic structure and diversity of ajowan (Trachyspermum ammi) populations based on molecular morphological markers, and volatile oil content. Industrial Crops and Products, 2016. 92: p. 186-196.

32. Chombe, D., and E., Bekele, Genetic diversity analysis of cultivated Korarima [Aframomum corrorima (Braun) P.C.M. Jansen] populations from southwestern Ethiopia using inter simple sequence repeats (ISSR) marker. Journal of Biological Research-Thessaloniki, 2018. 25: 1.

33. Hashemifar, Z., and M., Rahimmalek, Genetic structure and variation in Perovskia abrotanoides Karel and $P$. atriplicifolia as revealed by molecular and morphological markers. Scientia Horticulturae, 2018. 230: p. 169-177.

34. Abraham, E.M., et al., Genetic diversity of Thymus sibthorpii Bentham in mountainous natural grasslands of Northern Greece as related to local factors and plant community structure. Industrial Crops and Products, 2018. 111: p. 651-659.

35. Kuhn, D., Design of an Illumina Infinium 6k SNPchip for genotyping two large avocado mapping populations, in Proceedings of the 20th Conference on Plant andAnimal Genome. 2012: SanDiego, Calif, USA.

36. Lee, O.R., M.K., Kim, and D.C., Yang, Authentication of medicinal plants by SNP-based multiplex PCR, in: Plant DNA fingerprinting and barcoding: methods and protocols. 2012, New York: Humana Press, p. 135-147.

37. Manivannan, A., et al., Next-generation sequencing approaches in genome-wide discovery of single nucleotide polymorphism markers associated with pungency and disease resistance in pepper. BioMed Research International, 2018. https://doi.org/10.1155/2018/5646213.

38. Collard, B.C.Y., and D.J., Mackill, Start codon targeted (SCoT) polymorphism: a simple, novel DNA marker technique for generating gene-targeted markers in plants. Plant Molecular Biology Reporter, 2009. 27: p. 86-93.

39. Bhattacharyya, P., S., Kumaria, S., Kumar, and P., Tandon, Start codon targeted (SCoT) marker reveals genetic diversity of Dendrobium nobile Lindl., an endangered medicinal orchid species. Gene, 2013. 529: p. 21-26.

40. Singh, N., et al., Genetic stability in micropropagated Cleome gynandra revealed by SCoT analysis. Acta Physiologiae Plantarum, 2014. 36: p. 555-559.

41. Tiwari, G., et al., Study of arbitrarily amplified (RAPD and ISSR) and gene targeted (SCoT and CBDP) markers for genetic diversity and population structure in Kalmegh [Andrographis paniculata, (Burm. f.) Nees]. Industrial Crops and Products, 2016. 86: p. 1-11.

42. Mao, R., P., Xia, J., Liu, X., Li, R., Han, F., Liu, H., Zhao, and Z., Liang, Genetic diversity and population structure assessment of Chinese Senna obtusifolia L. by molecular markers and morphological traits of seed. Acta Physiologiae Plantarum, 2018. 40: 12. 
43. Xiang, X.G., et al., Molecular systematics of Dendrobium (Orchidaceae, Dendrobieae) from mainland Asia based on plastid and nuclear sequences. Molecular Phylogenetics and Evolution, 2013. 69: 950-960.

44. Jiang, C., Y., Luo, Y., Yuan, X., Dong, Y., Zhao, and L., Huang, Conventional octaplex PCR for the simultaneous identification of eight mainstream closely related Dendrobium species. Industrial Crops and Products, 2018. 112: p. 569-576.

45. Kshirsagar, P., S., Umdale, J., Chavan, and N., Gaikwad, Molecular authentication of medicinal plant, Swertia chirayita and its adulterant species, Proceedings of the National Academy of Sciences, India Section B: Biological Sciences, 2017. 87(1): p. 101-107.

46. Lee, S-C., C-H., Wang, C-E., Yen, and C., Chang, DNA barcode and identification of the varieties and provenances of Taiwan's domestic and imported made teas using ribosomal internal transcribed spacer 2 sequences, Journal of Food and Drug Analysis, 2017, 25: p. 260-274.

47. Hollingsworth, P.M., S.W., Graham, and D.P. Little, Choosing and Using a Plant DNA Barcode. PLoS ONE, 2011. 6: e19254.

48. Ali, M.A., G., Gyulai, and F. Al-Hermaid, Plant DNA Barcoding and Phyogenetics, LAP Lambert Academic Publishing, 2015, Saarbrücken, Germany.

49. Sucher, N.J., and M.C., Carles, Genome-based Approaches to the authentication of medicinal plants. Planta Medica, 2008. 74: p. 603-623.

50. Bhagyawant, S.S., RAPD-SCAR markers: an interface tool for authentication of Traits. Journal of Biosciences and Medicines, 2016. 4: p. 1-9.

51. Daniell, H., C.S., Lin, M., Yu, and W.J. Chang, Chloroplast genomes: diversity, evolution, and applications in genetic engineering. Genome Biology, 2016. 17: 134.

52. $\quad$ Fu, J., L., Yang, M.A., Khan, Z., Mei, Genetic characterization and authentication of Lonicera japonica Thunb. by using improved RAPD analysis. Molecular Biology Reports, 2013. 40: p. 5993-5999.

53. Moon, B.C., et al., Differentiating Authentic adenophorae radix from its adulterants in commercially-processed samples using multiplexed ITS sequence-based SCAR markers. Applied Sciences, 2017. 7: 660.

54. Fu, S., et al., Development of diagnostic SCAR markers for genomic DNA amplifications in breast carcinoma by DNA cloning of high-GC RAMP-PCR fragments. Oncotarget, 2017. 8: p. 4386643877.

55. Rafalski, J.A., and S.V. Tingey, Genetic diagnostics in plant breeding: RAPDs, microsatellites and machines. Trends in Genetics, 1993. 9: p. 275-280.

56. Rafalski, J.A., Novel genetic mapping tools in plants: SNPs and LD-based approaches. Plant Science, 2002. 162: p. 329-333. 